Research

Open Access

\title{
Tirofiban preserves platelet loss during continuous renal replacement therapy in a randomised prospective open-blinded pilot study
}

\author{
Andreas Link1, Matthias Girndt², Simina Selejan¹, Ranja Rbah¹ and Michael Böhm¹
}

\author{
${ }^{1}$ Klinik für Innere Medizin III, Universitätsklinikum des Saarlandes, Kirrberger Strasse, 66421 Homburg/Saar, Germany \\ ${ }^{2}$ Klinik für Innere Medizin IV, Universitätsklinikum des Saarlandes, Kirrberger Strasse, 66421 Homburg/Saar, Germany \\ Corresponding author: Andreas Link, link@med-in.uni-saarland.de
}

Received: 8 Apr 2008 Revisions requested: 16 May 2008 Revisions received: 16 Jun 2008 Accepted: 29 Aug 2008 Published: 29 Aug 2008

Critical Care 2008, 12:R111 (doi:10.1186/cc6998)

This article is online at: http://ccforum.com/content/12/4/R111

(C) 2008 Link et al.; licensee BioMed Central Ltd.

This is an open access article distributed under the terms of the Creative Commons Attribution License (http://creativecommons.org/licenses/by/2.0), which permits unrestricted use, distribution, and reproduction in any medium, provided the original work is properly cited.

\begin{abstract}
Introduction Approximately one third of all patients with cardiogenic shock suffer from acute kidney injury. Percutaneous coronary intervention, intra-aortic balloon pump, and continuous renal replacement therapy (CRRT) require effective antiplatelet therapy and anticoagulation, resulting in a high risk for platelet loss and bleeding events. The reversible platelet glycoprotein Ilb/llla receptor inhibitor tirofiban was investigated to preserve platelet number and activation in a prospective open-blinded endpoint evaluation study.

Methods Forty patients with cardiogenic shock and acute kidney injury requiring CRRT were randomly assigned to two groups receiving unfractioned heparin (UFH) $(n=20)$ or a combined anticoagulation with UFH and tirofiban $(n=20)$. The primary endpoint was platelet loss during CRRT. Secondary

endpoints were urea reduction, haemofilter life span, bleeding events, and necessity for platelet transfusions.

Results In UFH-treated patients, the percentage of plateletmonocyte aggregates significantly increased $(P<0.001)$ and consecutively platelet cell count significantly decreased $(P<$ $0.001)$. In contrast, combined treatment with UFH and tirofiban significantly decreased platelet-monocyte aggregates and platelet numbers $(P<0.001)$.

Conclusions This pilot study provides evidence that the use of tirofiban in addition to UFH prevents platelet loss and preserves platelet function in patients with cardiogenic shock and acute kidney injury requiring CRRT. The pathophysiological inhibition of platelet aggregation and platelet-monocyte interaction appears to be causally involved.
\end{abstract}

\section{Introduction}

Approximately one third of all patients with cardiogenic shock suffer from acute kidney injury. This increases in-hospital mortality from $53 \%$ to $87 \%$ [1]. Early revascularisation, intra-aortic balloon pump (IABP), and antithrombotic therapy improve outcomes in cardiogenic shock [2]. In cases of acute kidney injury with necessity for continuous renal replacement therapy (CRRT), effective anticoagulation is required. However, excessive anticoagulation in critically ill patients receiving CRRT may cause changes in platelet function, platelet loss, and bleeding events $[3,4]$.

The contact of blood with surfaces of the extracorporeal membrane circuits and different anticoagulants leads to platelet and leukocyte activation $[5,6]$ and platelet-leukocyte coaggregation $[7,8]$. All of these interactions result in glycoprotein (GP) Ilb/llla receptor activation that becomes capable of binding soluble fibrinogen [9]. GP Ilb/llla receptor antagonists primarily act on the platelet surface by inhibition of fibrinogen binding that is essential for platelet bridging and aggregate formation [10].

Tirofiban is a reversible short-acting inhibitor of platelet GP Ilb/ Illa receptors used in acute coronary syndromes and cardiac interventions [11]. The hypothesis that tirofiban preserves platelet number and function and shortens postoperative bleeding times was first described in baboons [12] and in patients with heparin-induced thrombocytopenia type II (HIT- 
II) during cardiopulmonary bypass surgery $[13,14]$. The aim of this study was to prove the efficacy of tirofiban on platelet protection and safety in critically ill patients with cardiogenic shock and necessity for CRRT receiving either conventional therapy with unfractionated heparin (UFH) or additional tirofiban.

\section{Materials and methods}

The PROBE (prospective randomised open-blinded endpoint) design study was approved by the ethics committee of the state medical board. Patients with cardiogenic shock $(n=$ 187 ) and acute kidney injuries with necessity for CRRT ( $\mathrm{n}=$ 52) were evaluated from January 2006 to December 2007. Cardiogenic shock was confirmed by both clinical and haemodynamic criteria. The clinical criteria were hypotension (systolic blood pressure of less than $90 \mathrm{~mm} \mathrm{Hg}$ for at least 30 minutes or the need for supportive vasoactive medications to maintain a systolic blood pressure of greater than $90 \mathrm{~mm} \mathrm{Hg}$ ) and evidence of end-organ hypoperfusion (cool, diaphoretic extremities). Haemodynamic criteria were a reduced cardiac index $\left(<2.2 \mathrm{~L} /\right.$ minute per $\left.\mathrm{m}^{2}\right)$ and the presence of elevated pulmonary capillary occlusion pressure $(>15 \mathrm{~mm} \mathrm{Hg})$ [15]. Acute kidney injury with necessity for CRRT was defined as a urine output of less than $0.5 \mathrm{~mL} / \mathrm{kg}$ per hour for 6 hours and/ or an increase in serum creatinine of greater than or equal to $1.5 \mathrm{mg} / \mathrm{dL}$ within 24 hours according to the RIFLE (Risk, Injury, Failure, Loss, and End-stage kidney disease) criteria grade risk of renal dysfunction [16]. After admission to the intensive care unit (ICU) and after informed consent was given, all study participants $(n=40)$ were randomly assigned using a computer algorithm: UFH $(n=20)$ versus UFH + tirofiban $(n=20)$. Figure 1 outlines data on patient enrolment, exclusion criteria, and follow-up. The primary endpoint was platelet loss during CRRT. Secondary outcomes were the efficacy of CRRT, measured by steady-state blood urea nitrogen (BUN) during CRRT, the need for platelet substitution (platelet count of less than $20 \times 10 \% / \mathrm{L}$ ) and major bleeding signs. Major bleeding included any bleeding requiring surgical intervention with a timely connection with CRRT, bleeding documented by computed tomography and/or ultrasound (intracerebral as well as retroperitoneal, abdominal, intestinal, or urogenital) or a decrease in haemoglobin of greater than $5 \mathrm{~g} / \mathrm{dL}$ within 72 hours with a timely connection with CRRT. Minor bleeding involves a haemoglobin drop of less than or equal to $5 \mathrm{~g} / \mathrm{dL}$ with or without an identified bleeding site.

CRRT was performed as continuous veno-venous haemodialysis, using a pump system (ADM; Fresenius, Bad Homburg, Germany) and capillary polysulfone haemofilters (Ultraflux ${ }^{\circledR} \mathrm{AV}$ 1000S; Fresenius). Blood flow ranged from 100 to $120 \mathrm{~mL} /$ hour. Dialysis flow was, on average, $2,000 \mathrm{~mL} /$ hour. The ultrafiltration rate was adjusted to patient hydratation and haemodynamic status. Haemofilters and tubing were changed routinely every 24 hours according to the manufacturer's recommendations. Therefore, blood was reinfused to the patient and the entire set of single-use tubes was changed together with the haemofilter. Blood products were administered during a CRRT pause if necessary when haemofilters were changed. The efficacy of CRRT was measured by mean treatment dose and steady-state BUN during CRRT [17]. The study drugs standard unfractioned heparin (UFH) and tirofiban were administered into the extracorporeal circuit as a prefilter infusion. All patients received UFH (Heparin-Natrium-ratiopharm ${ }^{\circledR}$; ratiopharm $\mathrm{GmbH}, \mathrm{Ulm}$, Germany) by intravenous bolus application of $80 \mathrm{IU} / \mathrm{kg}$ followed by a continuous infusion with 18 $\mathrm{IU} / \mathrm{kg}$ per hour. For UFH dose titration, plasma activated partial thromboplastin time (aPTT) was measured every hour until a two- to three-fold aPTT was reached. In cases of a steady state, CRRT was started and aPTT was measured twice daily. The short-acting reversible GP Ilb/llla inhibitor tirofiban (Aggrastat ${ }^{\circledR} ;$ MSD Sharp \& Dohme GmbH, Haar, Germany) has a protein binding of $65 \%$ and an elimination half-life of 1.5 to 2 hours predominantly achieved via the renal pathway. According to the manufacturer's recommendations for severe renal insufficiency (creatinine clearance of less than $30 \mathrm{~mL} / \mathrm{minute}$ ), patients of the tirofiban group received, in addition to UFH, tirofiban by intravenous bolus application of $0.2 \mu \mathrm{g} / \mathrm{kg}$ per minute over 30 minutes followed by a continuous infusion with $0.05 \mu \mathrm{g} / \mathrm{kg}$ per minute. According to clinical guidelines, prophylactic platelet transfusions are recommended beyond a platelet count of less than $10 \times 109 / \mathrm{L}$ [18]. Because of the offlabel use of tirofiban, the threshold level for prophylactic platelet transfusion was changed to $20 \times 10 \% / \mathrm{L}$.

\section{Laboratory tests}

To determine changes in haemostasis during the passage of blood through the extracorporeal circuit, blood was sampled in citrate tubes from the efferent line of the extracorporeal circulation (postfilter). All tests were performed in duplicate. Blood samples for analysis of full clinical chemistry, haematology, and platelet-monocyte aggregates were taken before starting CRRT and the following 4 days after starting treatment. The bleeding time was measured by the standardised lvy method [19]. Other causes of platelet loss were excluded by HIT-II screening tests using the particle gel immunoassay (ID-HPF4; DiaMed, Cressier, Switzerland) for rapid detection and the enzyme-linked immunosorbent assay for discovering antibodies ( $\lg G, \lg A$, and $\lg M)$ to heparin-platelet factor-4 complexes. Both HIT-Il tests were done for all patients. Flow cytometry is a sensitive technique that permits the use of whole blood to assess platelet function in a physiological manner although the interaction of blood with the endothelium is excluded [20]. Staining platelets with antibodies was performed immediately after blood collection, avoiding artificial platelet activation and aggregation. Platelets were identified by monoclonal antihuman antibodies directed against CD41 (clone HIP8, phycoerythrin-conjugated; BD Pharmingen, Heidelberg, Germany), the activated form of GP Ilb/llla receptors by PAC-1 (clone $P A C-1$, fluorescein isothiocyanate-conjugated; BD Pharmingen), and monocytes by CD14 (clone RMO52, phycoerythrin- 


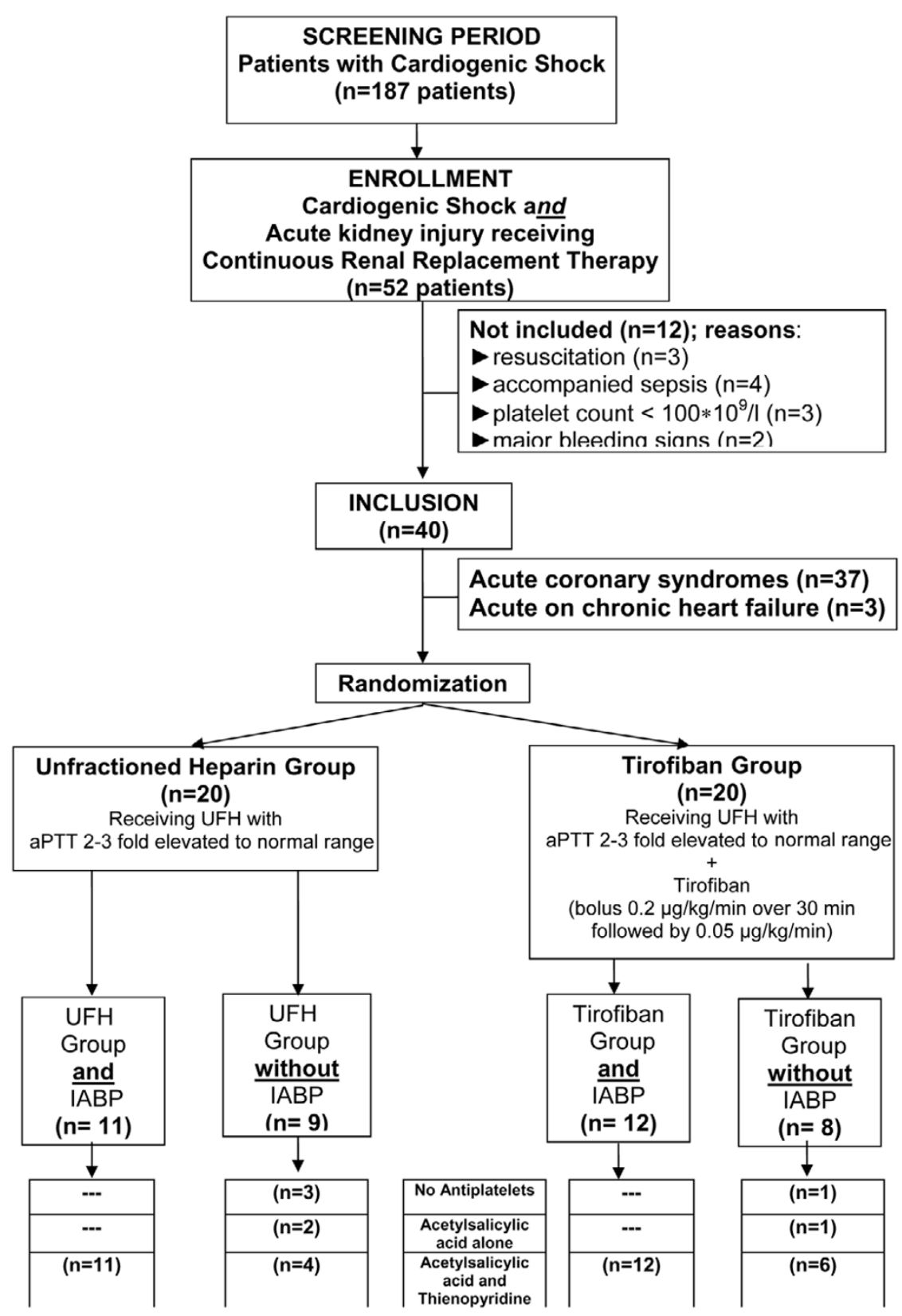

Study flowchart. Patients were randomly assigned in different anticoagulation regimens (unfractioned heparin [UFH] versus UFH + tirofiban), separated according to the concomitant therapy with or without intra-aortic balloon pump (IABP). Furthermore, the concomitant antiplatelet therapy and the number of patients included in each subgroup were added. Exclusion criteria include cardiopulmonary resuscitation, suspected concomitant sepsis defined by haemodynamic criteria (reduced systemic vascular resistance), a platelet count of less than $100 \times 10^{9 / L}$, or major bleeding signs (one patient retroperitoneal and one patient gastric haemorrhage). aPTT, activated partial thromboplastin time.

cyanin [PECy5]-conjugated; Beckman Coulter, Krefeld, Germany). Increases in PAC-1 have been shown to be directly correlated with the activation of GP Ilb/llla binding to fibrinogen and/or monocytes. Measurements were performed by flow cytometer (FACSCalibur; Becton Dickinson, Heidelberg, Germany) and the Cellquest software system (Becton Dickinson, Heidelberg, Germany). Monocytes were selectively gated for analysis by forward scatter, side scatter, and CD14-
PECy5. The percentages of PAC-1+/CD41 ${ }^{+} / C D 14^{+}$plateletmonocyte aggregates were measured. Nonspecific immunofluorescence was determined using unspecific control monoclonal antibodies.

\section{Statistical methods}

The sample size calculation was performed by the software of the Survey System (Creative Research Systems, Petaluma, 
CA, USA). The sample size was calculated by the following acceptations: a platelet loss of more than $50 \%$ to baseline and a variability of platelet counts of $15 \%$. To detect platelet loss with a power of $95 \%$, a sample size of at least 20 patients in each study group was required. To compare the two treatment regimens, the Mann-Whitney $U$ test and analysis of variance were used. Data were given as mean \pm standard deviation. Differences were considered significant if the $P$ value was less than 0.05 . Observed-to-expected (O/E) mortality ratios were reported for each group using the observed-to-SAPS II (Simplified Acute Physiology Score) expected rates per group. Ninety-five percent confidence intervals were calculated.

\section{Results}

Forty patients with cardiogenic shock and acute kidney injuries receiving CRRT were studied for an alternative anticoagulation regimen with the GP Ilb/llla receptor antagonist tirofiban. Baseline characteristics of the patients are shown in Table 1. All baseline characteristics were well balanced between the treatment groups. Thirty-six of the patients had an acute myocardial infarction, and only four patients had a cardiogenic shock based on acute on chronic heart failure. Clinical proce- dures are summarised in Table 2. All patients with acute coronary syndromes received a percutaneous coronary intervention, and in 23 cases an IABP was implanted. Most patients received vasoactive therapy at randomisation and during the whole study period of 4 days.

Platelet counts are shown in Figure 2. Baseline platelet counts in the two treatment groups were equivalent (194 \pm 39.5 versus $216 \pm 64.3 \times 10^{9} / \mathrm{L}, P=$ n.s. [not significant], $\mathrm{n}=20$ ). Already after 1 day, patients assigned to tirofiban + UFH had a significant higher platelet count compared with patients assigned to UFH (172 \pm 52.9 versus $121 \pm 49.2 \times 10^{9} / \mathrm{L}, P$ $=0.003, \mathrm{n}=20$ ). This difference between the two treatment groups continued over the study period up to 4 days (158 \pm 45.3 versus $\left.87.3 \pm 41.1 \times 10^{9} / \mathrm{L}, P<0.0001, \mathrm{n}=20\right)$.

The influence of IABP treatment on platelet count is shown in Figure 2. At day 2, which is the mean IABP duration, there was no significant difference in platelet count between the UFH groups with or without IABP. In the same way, no significant differences could be observed in the tirofiban groups with or

Table 1

\section{Demographic and baseline clinical characteristics of patients}

\begin{tabular}{|c|c|c|c|}
\hline & UFH $(n=20)$ & UFH + tirofiban $(n=20)$ & $P$ value \\
\hline \multicolumn{4}{|l|}{ Demographic data } \\
\hline Age in years, median (range) & $71(44,85)$ & $70(52,81)$ & 0.932 \\
\hline Female/male, number & $8 / 12$ & $9 / 11$ & 0.757 \\
\hline \multicolumn{4}{|l|}{ Severity of illness scores } \\
\hline APACHE II score, median (range) & $27(18,34)$ & $28(18,34)$ & 0.523 \\
\hline SAPS II, median (range) & $46(31,66)$ & $48(30,64)$ & 0.768 \\
\hline \multicolumn{4}{|l|}{ Cardiogenic shock: reasons and haemodynamics at admission } \\
\hline Acute coronary syndromes, number & 17 & 19 & 0.304 \\
\hline Acute decompensation of $\mathrm{CHF}$, number & 3 & 1 & 0.304 \\
\hline Left ventricular ejection fraction as a percentage, median (range) & $31(20,57)$ & $30(18,54)$ & 0.446 \\
\hline Cardiac index in L/minute per square metre, median (range) & $2(1.4,2.4)$ & $2(1.6,2.4)$ & 0.955 \\
\hline \multicolumn{4}{|l|}{ Renal failure: reasons and parameters at admission } \\
\hline Acute kidney injury, number & 16 & 17 & 0.688 \\
\hline Acute decompensation of CRI, number & 4 & 3 & 0.688 \\
\hline Creatinine in $\mathrm{mg} / \mathrm{dL}$, mean $\pm \mathrm{SD}$ & $2.9 \pm 0.3$ & $2.5 \pm 0.2$ & 0.788 \\
\hline Blood urea nitrogen in $\mathrm{mg} / \mathrm{dL}$, mean $\pm \mathrm{SD}$ & $72 \pm 23.3$ & $70 \pm 24.1$ & 0.734 \\
\hline \multicolumn{4}{|l|}{ Haematology } \\
\hline Platelet count, $\times 10^{9} / \mathrm{L}$, mean $\pm \mathrm{SD}$ & $216 \pm 64.3$ & $194 \pm 39.5$ & 0.212 \\
\hline Monocyte count, $\times 10^{6} / \mathrm{L}$, mean \pm SD & $1,059 \pm 85.4$ & $981 \pm 103$ & 0.561 \\
\hline Platelet-monocyte aggregates as a percentage, mean \pm SD & $20.2 \pm 5.9$ & $20.8 \pm 6.1$ & 0.751 \\
\hline
\end{tabular}

APACHE, Acute Physiology and Chronic Health Evaluation; CHF, chronic heart failure; CRI, chronic renal insufficiency; SAPS, Simplified Acute Physiology Score; SD, standard deviation; UFH, unfractioned heparin. 


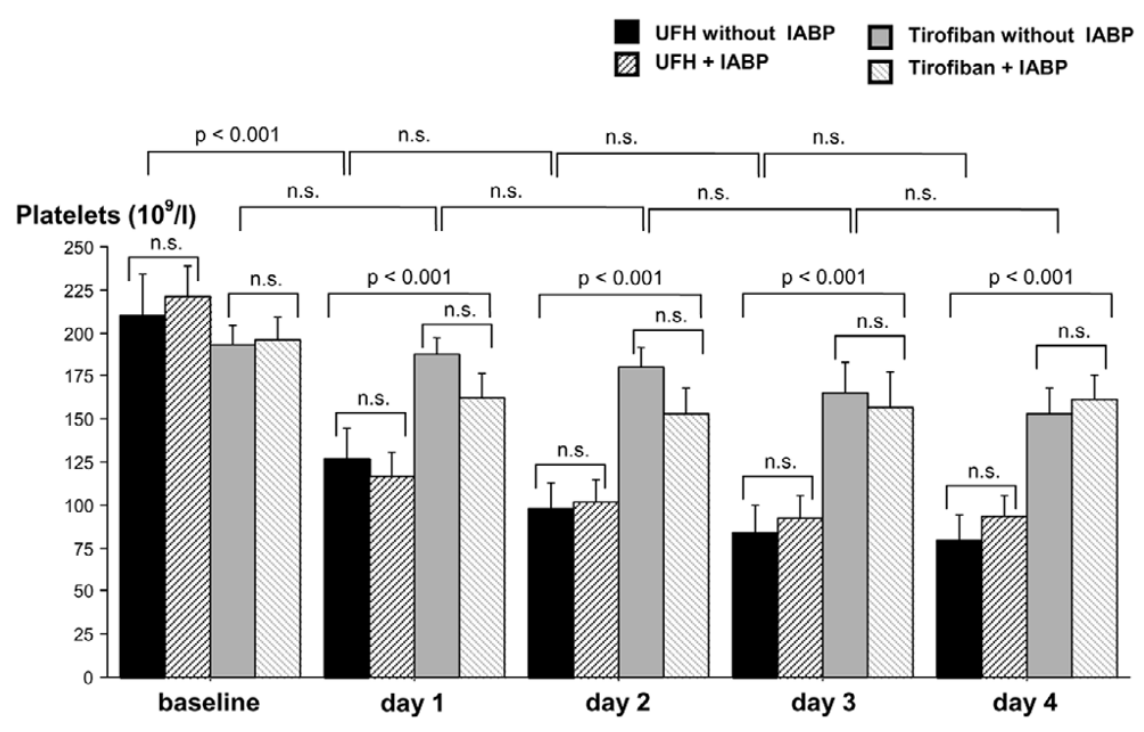

Mean platelet counts during the study period in patients treated with unfractioned heparin (UFH) versus UFH + tirofiban and with or without intraaortic balloon pump (IABP). Data are shown as mean \pm standard deviation. n.s., not significant.

without IABP. Similarly, no differences in platelet count in patients with or without IABP were detected on days 3 and 4. After discontinuation of IABP, no significant increase in platelet count was observed for either the UFH or the tirofiban group until the end of the study period.

Besides the different anticoagulation with UFH or UFH and tirofiban, the patients were treated with different antiplatelet regimens (no antiplatelets, acetylsalicylic acid alone, or combined antiplatelet therapy with acetylsalicylic acid and thienopyridine) (Table 2). Since the number of patients in the subgroups with no antiplatelet therapy or with acetylsalicylic acid alone was too low, no statistical analysis could be performed. But, as shown in Figure 3, the course of platelet count was comparable in the three antiplatelet subgroups during the whole study period.

The efficacy of CRRT was estimated by mean treatment dose, steady-state BUN during CRRT, and haemofilter life span. The calculated mean treatment dose was 25 to $30 \mathrm{~mL} / \mathrm{kg}$ per hour in both anticoagulation regimens and confirmed by an acceptable steady-state BUN during CRRT (Table 2).

The platelet transfusion threshold was defined as a platelet count of less than $20 \times 10 \% / \mathrm{L}$. During the study period, in three patients of the UFH group, a platelet loss of less than $20 \times$ $10 \% / \mathrm{L}$ was registered without any bleeding signs. Two patients received one platelet unit and one patient needed two units for platelet increase. The number of platelet units related to the cumulative days of CRRT was calculated as $0.05 \pm 0.02$. In the tirofiban group, no platelet transfusion was necessary. Thus, the difference of platelet transfusions between the two groups was significant $(P=0.016, \mathrm{n}=20)$ (Table 3$)$.
The study was not powered for mortality. The in-hospital mortality rates were $35 \%$ in the UFH + tirofiban group and $40 \%$ in the UFH group. ICU mortality, hospital mortality, O/E mortality ratios, and 95\% confidence intervals were calculated (Table 3).

In all patients, the baseline levels of monocytes were not different between the two anticoagulation regimens (UFH + tirofiban versus UFH: $981 \pm 103.6$ versus $1,059 \pm 85.4 \times$ $10^{6} / \mathrm{L}, \mathrm{n}=20, P=$ n.s.). During CRRT with UFH + tirofiban, monocyte counts increased significantly $(1,394 \pm 151$ versus $\left.945 \pm 77.3 \times 10^{6} / \mathrm{L}, \mathrm{n}=20, P=0.012\right)$. The percentage of PAC-1/CD41a-positive monocytes before starting CRRT was equivalent between the two anticoagulation regimens $(20.8 \%$ $\pm 6.1 \%$ versus $20.2 \% \pm 5.9 \%, \mathrm{n}=20, P=$ n.s.). Within 24 hours, the combined UFH + tirofiban anticoagulation resulted in a decrease of PAC-1/CD41a-positive platelet-monocyte coaggregates whereas with UFH alone these coaggregates increased $(9.5 \% \pm 5.8 \%$ versus $27.5 \% \pm 9.3 \%, \mathrm{n}=20, P<$ $0.001)$. The follow-up of 4 days presented a further decrease of platelet-monocyte coaggregates in the tirofiban group; within the UFH group, the coaggregates remained stable but elevated to baseline $(27.5 \% \pm 9.3 \%$ versus $20.2 \% \pm 5.9 \%, n$ $=20, P<0.001)$. This difference between the two anticoagulation regimens was already present after 24 hours of treatment (Figure 4).

\section{Discussion}

In a pilot study, we investigated the possible use and effectiveness of the reversible platelet GP Ilb/llla receptor inhibitor tirofiban to preserve platelet number and function during CRRT in patients with cardiogenic shock. Tirofiban additional to UFH for anticoagulation apparently prevented platelet loss 
Table 2

\begin{tabular}{|c|c|c|c|}
\hline & UFH $(n=20)$ & UFH + tirofiban $(n=20)$ & $P$ value \\
\hline \multicolumn{4}{|l|}{ Cardiac procedures } \\
\hline Coronary angiography, number & 18 & 19 & 0.560 \\
\hline Percutaneous coronary intervention, number & 15 & 18 & 0.560 \\
\hline Intra-aortic balloon pump, number & 11 & 12 & 0.876 \\
\hline Intra-aortic balloon pump duration in hours, mean \pm SD & $48 \pm 14.4$ & $50 \pm 12.5$ & 0.757 \\
\hline \multicolumn{4}{|l|}{ Haemodialysis characteristics } \\
\hline Treatment dose in $\mathrm{mL} / \mathrm{kg}$ per hour, mean $\pm \mathrm{SD}$ & $28 \pm 2.5$ & $28 \pm 2.9$ & 0.381 \\
\hline \multicolumn{4}{|l|}{ Blood urea nitrogen (BUN) } \\
\hline Pretreatment BUN in $\mathrm{mg} / \mathrm{dL}$, mean $\pm \mathrm{SD}$ & $72 \pm 23.3$ & $70 \pm 24.1$ & 0.734 \\
\hline Steady-state BUN during CRRT in $\mathrm{mg} / \mathrm{dL}$, mean $\pm \mathrm{SD}$ & $32 \pm 18.1$ & $31 \pm 22.1$ & 0.734 \\
\hline \multicolumn{4}{|l|}{ Antiplatelet therapy and anticoagulation } \\
\hline No antiplatelets, number & 3 & 1 & - \\
\hline Acetylsalicylic acid alone, number & 2 & 1 & - \\
\hline Acetylsalicylic acid and thienopyridine, number & 15 & 18 & - \\
\hline UFH, number (dose in IU/kg per hour, mean \pm SD) & $20(18.4 \pm 0.6)$ & $20(18.2 \pm 0.8)$ & 0.872 \\
\hline Activated partial thromboplastin time in seconds, mean \pm SD & $64 \pm 13.2$ & $62 \pm 11.8$ & 0.621 \\
\hline Ivy bleeding time in seconds, mean $\pm \mathrm{SD}$ & $422 \pm 58.1$ & $599 \pm 118.1$ & 0.003 \\
\hline \multicolumn{4}{|l|}{ Further concomitant therapy } \\
\hline Dobutamine, number (dose in $\mu \mathrm{g} / \mathrm{kg}$ per minute, mean $\pm \mathrm{SD}$ ) & $18(6 \pm 2.8)$ & $19(6 \pm 3.2)$ & 0.560 \\
\hline Norepinephrine, number (dose in $\mu \mathrm{g} / \mathrm{kg}$ per minute, mean $\pm \mathrm{SD}$ ) & $14(0.2 \pm 0.1)$ & $13(0.2 \pm 0.15)$ & 0.744 \\
\hline Opioids and benzodiazepins, number & 12 & 14 & 0.519 \\
\hline Mechanical ventilation, number & 12 & 14 & 0.519 \\
\hline
\end{tabular}

CRRT, continuous renal replacement therapy; SD, standard deviation; UFH, unfractioned heparin.

over a period of 96 hours of CRRT. Furthermore, the inhibition of the activated platelet fibrinogen receptor GP Ilb/Illa (PAC1) by tirofiban results in an inhibition of platelet-leukocyte interaction and aggregation $[7,8,21]$. We examined changes in platelet loss and platelet-monocyte coaggregates by analysing the platelet-specific CD41a and PAC-1 antigen on monocytes using three-color flow cytometry as whole-blood technique. The percentage of platelet-monocyte coaggregates showed a highly significant decrease by combined anticoagulation with UFH and tirofiban. Platelet-monocyte aggregates were shown to promote monocyte adhesion to endothelium and to induce proinflammation [22-25]. Our findings suggest that the combined anticoagulation with UFH and tirofiban during CRRT inhibits platelet activation and platelet-monocyte interactions with consequences for platelet protection and antithrombotic and anti-inflammatory effects. In contrast, the treatment with UFH alone increased platelet-monocyte binding.

Platelet loss under CRRT in the UFH group was marked. This may be related to the critically ill patients with cardiogenic shock combined with acute kidney injury. Our results are comparable to other examinations of critically ill patients with multiple organ dysfunction syndrome and acute kidney injuries [26]. Neither the concomitant treatment with intra-aortic counterpulsation nor the antiplatelet therapy with acetylsalicylic acid and thienopyridine had an effect on the platelet loss between these subgroups.

The efficacy of CRRT assessed by mean treatment doses and steady-state BUN during CRRT was comparable in the two treatment groups. Despite the different anticoagulation regimens and the higher potency of anticoagulation within the tirofiban + UFH group, this therapy was not associated with an increased number of bleeding events. To minimise the risk of bleeding, tirofiban and UFH were administered into the extracorporeal circuit as a prefilter infusion. The study was not focused on bleeding events and therefore an analysis regarding bleeding events would be totally underpowered. But as a result, no clinically important bleedings were detected and no transfusions of red blood cells or platelet units were necessary 


\section{Unfractioned Heparin Group}

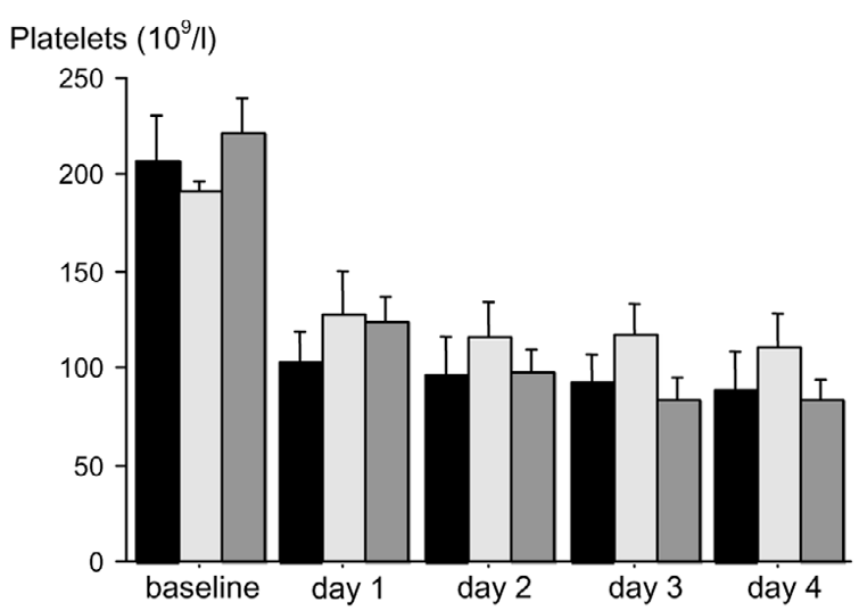

\section{Tirofiban Group}

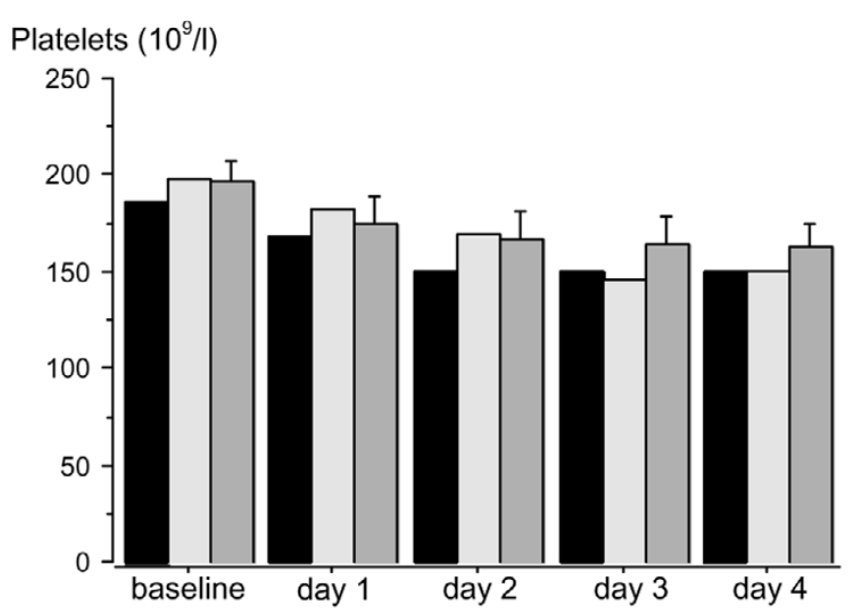

Mean platelet counts during the study period in patients treated with unfractioned heparin (UFH) versus UFH + tirofiban and with different antiplatelet therapy regimens. Data are shown as mean \pm standard deviation.

in patients treated with the combined tirofiban + UFH anticoagulation. Nevertheless, further studies are warranted to ascertain the safety of an anticoagulation regimen with tirofiban + UFH during long-term CRRT.

One might argue that the study could be limited by (a) the open-label character of its design, (b) the small number of patients, (c) the lack of a specific antidote for tirofiban, and (d) missing data on long-term efficacy and bleeding events of tirofiban during CRRT. Because of the pilot-study character and the off-label use of tirofiban during CRRT, the physicians were not blinded. However, clinical evaluation and determination of primary endpoints were done separately by clinical and experimental investigators, the latter of which were blinded to the clinical data of the patients. As there is no specific antidote for tirofiban in cases of bleeding events, donor platelets should be transfused and haemofiltration is suggested for extracorporeal elimination of tirofiban [27]. A recent development of a rapid whole-blood point-of-care platelet function assay, the rapid platelet function assay, now allows for the bedside monitoring of platelet inhibition by GP Ilb/llla receptor antagonists [28]. Further investigations with larger numbers of patients are necessary for the determination of haemofilter run times, long-term efficacy, and bleeding events of tirofiban during CRRT.

\section{Conclusion}

The GP Ilb/llla receptor antagonist tirofiban inhibits platelet activation and platelet-monocyte interaction. Its use in addition to UFH during CRRT prevents platelet loss and preserves platelet function.

\section{Key messages}

- The glycoprotein Ilb/llla receptor antagonist tirofiban inhibits platelet activation and platelet-monocyte interaction.

- The use of tirofiban during continuous renal replacement therapy prevents platelet loss and preserves platelet function.

\section{Competing interests}

The authors declare that they have no competing interests. This study, which originally included 20 patients, was initiated with financial support from MSD Sharp \& Dohme $\mathrm{GmbH}$. Investigations of an additional 20 patients were financed by the authors.

\section{Authors' contributions}

AL helped to initiate the study, participated in the statistical analysis of the data and in interpreting the data, and drafted the manuscript. MG led CRRT and participated in the statistical analysis of the data and in interpreting the data. SS and RR participated in experimental investigations. MB helped to initi- 
Table 3

Primary and secondary endpoints

UFH $(n=20) \quad$ UFH + tirofiban $(n=20) \quad P$ value

Platelet/Monocyte counts at the end of CRRT

Platelet count, $\times 10 \% / \mathrm{L}$, mean $\pm \mathrm{SD}$

$\begin{array}{ccc}87 \pm 41.1 & 158 \pm 45.3 & 0.001 \\ 945 \pm 77.3 & 1,394 \pm 151 & 0.012 \\ 27.5 \pm 9.3 & 3.9 \pm 2.1 & 0.001\end{array}$

Platelet-monocyte aggregates as a percentage, mean \pm SD

$27.5 \pm 9.3$

$3.9 \pm 2.1$

0.001

Bleeding events during CRRT

Minor bleeding, number

Major bleeding, number

Platelet transfusions during CRRT

Platelet units per patient per day, mean \pm SD

Outcome

Intensive care unit mortality rate, number (percentage)

Hospital mortality rate, number (percentage)

SAPS II predicted mortality rate as a percentage

Observed-to-expected mortality ratio

95\% confidence interval for the observed-to-expected mortality ratio
2

0

$\begin{array}{cc}1 & 0.560 \\ 0 & 1 \\ 0 & 0.016\end{array}$

$0.05 \pm 0.02 \quad 0.016$

$\begin{array}{lll}8(40) & 7(35) & 0.752 \\ 8(40) & 7(35) & 0.752\end{array}$

$36.9 \quad 41.4$

1.08

0.85

$0.46,1.97 \quad 0.34,1.59$

Values are presented as number of patients or mean \pm standard deviation (SD). CRRT, continuous renal replacement therapy; SAPS, Simplified Acute Physiology Score; UFH, unfractioned heparin.

ate the study and participated in the statistical analysis of the data and in interpreting the data. All authors read and approved the final manuscript.

Figure 4

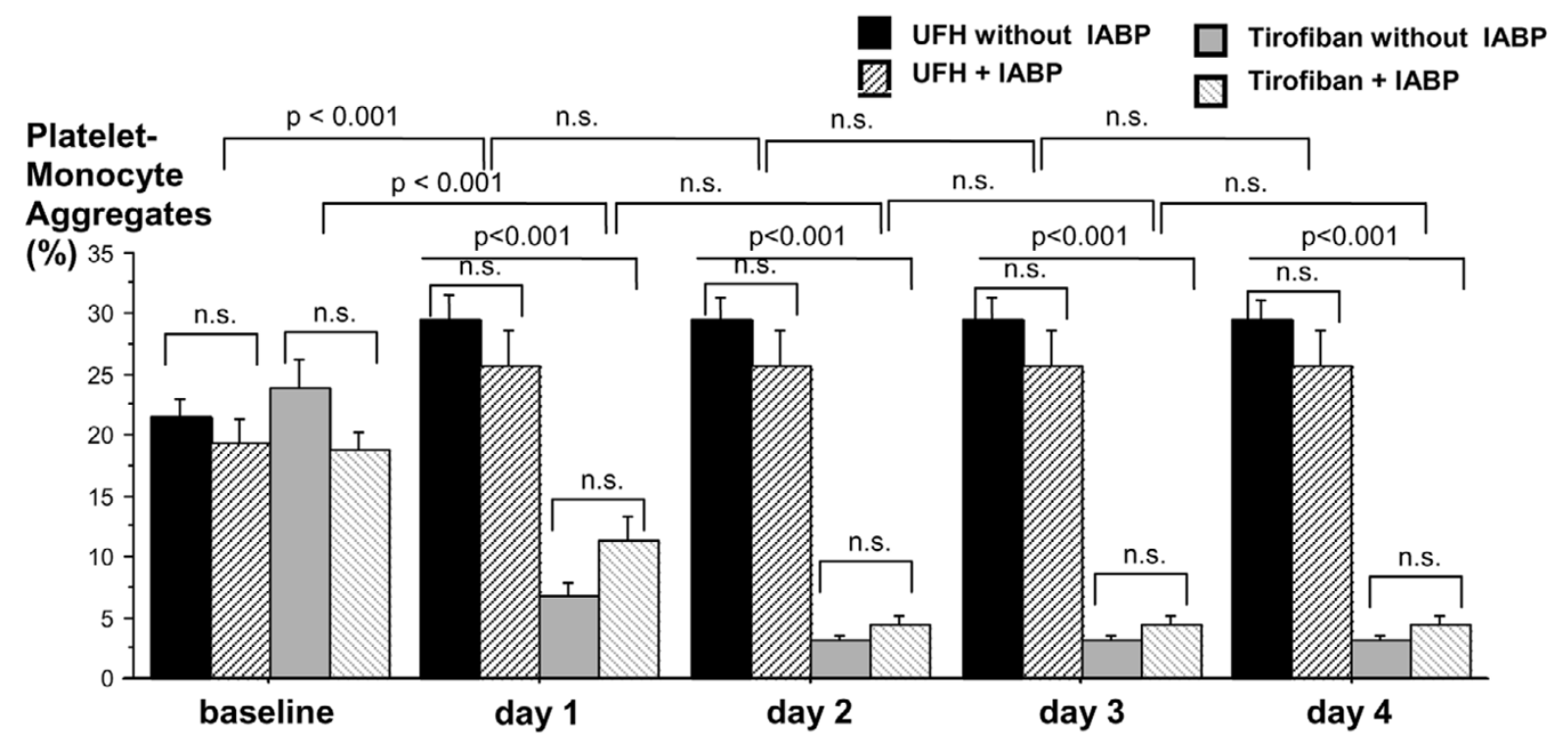

Mean platelet-monocyte aggregates during the study period in patients treated with unfractioned heparin (UFH) versus UFH + tirofiban and with or without intra-aortic balloon pump (IABP). Data are shown as mean \pm standard deviation. n.s., not significant. 


\section{Acknowledgements}

We would like to thank all of the people who were involved in the study.

\section{References}

1. Koreny M, Karth GD, Geppert A, Neunteufl T, Priglinger U, Heinz G, Siostrzonek P: Prognosis of patients who develop acute renal failure during the first $\mathbf{2 4}$ hours of cardiogenic shock after myocardial infarction. Am J Med 2002, 112:115-119.

2. Hochmann JS, Sleeper LA, White HD, Dzavik V, Wong SC, Menon V, Webb JG, Steingart R, Picard MH, Menegus MA, Boland J, Sanborn T, Buller CE, Modur S, Forman R, Desvigne-Nickens $P$, Jacobs AK, Slater JN, LeJemtel TH, SHOCK Investigators: Should we emergently revascularize occluded coronaries for cardiogenic shock: one-year survival following early revascularization for cardiogenic shock. JAMA 2001, 285:190-192.

3. Bold J, Menges T, Wollbrück M, Sonneborn S, Hempelmann G: Continuous hemofiltration and platelet function in critically ill patients. Crit Care Med 1994, 22:1155-1160.

4. Mulder J, Tan HK, Bellomo R, Silvester W: Platelet loss across hemofilter during continuous hemofiltration. Int J Artif Organs 2003, 26:906-912.

5. Notohamiprodjo M, Andrassy K, Bommer J, Ritz E: Dialysis membranes and coagulation system. Blood 1986, 4:130-141.

6. Lins LE, Boberg $U$, Jacobson $\mathrm{SH}$, Kjellstrand $\mathrm{C}$, Ljungberg $B$, Skroder R: The influence of dialyzer geometry on blood coagulation and biocompatibility. Clin Nephrol 1993, 40:281-285.

7. Spangenberg P, Redlich H, Bergmann I, Losche W, Gotzrath M, Kehrel B: The platelet glycoprotein Ilb-Illa complex is involved in the adhesion of activated platelets to leukocytes. Thromb Haemost 1993, 70:514-521.

8. Gawaz MP, Mujais SK, Schmidt B, Blumenstein M, Gurland HJ: Platelet-leukocyte aggregates during hemodialysis: effect of membrane type. Artif Organs 1999, 23:29-36.

9. Kawabata K, Nakai S, Miwa M, Sugiura T, Otsuaka $Y$, Shinzato T, Hiki Y, Tomimatsu I, Ushida Y, Hosono F, Maeda K: Platelet GP $\mathrm{Ilb} / \mathrm{IIla}$ is activated and platelet-leukocyte coaggregates formed in vivo during hemodialysis. Nephron 2002, 90:391-400.

10. Gawaz MP, Mujais SK, Schmidt B, Burland HJ: Platelet-leukocyte aggregation during hemodialysis. Kidney Int 1994, 46:489-495.

11. The PRISM-Plus Investigators: Inhibition of the platelet glycoprotein Ilb/Illa receptor with tirofiban in unstable angina and non-Q-wave myocardial infarction. N Engl J Med 1998, 338:1488-1497.

12. Hiramatsu Y, Gikakis N, Anderson HL III, Gorman JH III, Marcinkiewicz C, Gould RJ, Niewiarowski S, Edmunds LH Jr: Tirofiban provides "platelet anaesthesia" during cardiopulmonary bypass in baboons. J Thorac Cardiovasc Surg 1997, 113:182-193.

13. Koster A, Kukucka M, Bach F, Meyer O, Fischer T, Mertzlufft F, Loebe M, Hetzer R, Kuppe H: Anticoagulation during cardiopulmonary bypass in patients with heparin-induced thrombocytopenia type II and renal impairment using heparin and the platelet glycoprotein Ilb/IIla antagonist tirofiban. Anesthesio/ogy 2001, 94:245-251.

14. Straub A, Azevedo R, Beierlein W, Wendel HP, Dietz K, Ziemer G: Tirofiban (Aggrastat ${ }^{\circledR}$ ) protects platelets and decrease platelet-granulocyte binding in an extracorporeal circulation model. J Thorac Cardiovasc Surg 2006, 54:162-167.

15. Hollenberg SM, Kavinsky CJ, Parrillo JE: Cardiogenic shock. Ann Intern Med 1999, 131:47-59.

16. Venkataraman R, Kellum JA: Defining acute renal failure: the RIFLE criteria. J Intensive Care Med 2007, 22:187-193.

17. Uchino S, Bellomo R, Morimatsu H, Morgera S, Schetz M, Tan I, Bouman C, Macedo E, Gibney N, Tolwani A, Oudemans-van Straaten $\mathrm{H}$, Ronco $\mathrm{C}$, Kellum JA: Continuous renal replacement therapy: a worldwide practice survey. The beginning and ending supportive therapy for the kidney (B.E.S.T. kidney) investigators. Intensive Care Med 2007, 33:1563-1570.

18. Greinacher A, Kiefel V, Klüter H, Kroll H, Pötzsch B, Riess H: Recommendations on platelet transfusion by the Joint Working Party of the German Society of Transfusion Medicine (DGTI), Thrombosis and Haemostasis Research (GTH), and Haemotology and Oncology (DGHO). Dtsch Med Wochenschr 2006, 131:2675-2679.
19. Mielke $\mathrm{CH}$, Kaneshiro MM, Maher IA: The standardised normal Ivy Bleeding Time and its prolongation by aspirin. Blood 1969 34:204-215.

20. Michelson AD: Flow cytometry: a clinical test of platelet function. Blood 1996, 87:4925-4936.

21. Shattil SJ, Hoxie JA, Cunningham M, Brass $L$ : Changes in the platelet membrane glycoprotein IIb-Illa complex during platelet activation. J Biol Chem 1985, 260:11107-11114.

22. Elstad MR, La Pine TR, Cowley FS, McEver RP, Mclntyre TM, Prescott SM, Zimmerman GA: P-selectin regulates platelet-activating factor synthesis and phagocytosis by monocytes. J Immunol 1995, 155:2109-2122.

23. Weyrich AS, Elstad MR, McEver RP, McIntyre TM, Moore KL, Morrissey JH, Prescott SM, Zimmerman GA: Activated platelets signal chemokine synthesis by human monocytes. J Clin Invest 1996, 97:1525-1534.

24. Neumann FJ, Zohlnhofer D, Fakhoury L, Ott I, Gawaz M, Schömig A: Effect of glycoprotein Ilb/IIla receptor blockade on plateletleukocyte interaction and surface expression of the leukocyte integrin MAC-1 in acute myocardial infarction. $J \mathrm{Am}$ Coll Cardiol 1999, 34:1420-1426.

25. da Costa Martins $\mathrm{P}$, Berk N van den, Ulfman LH, Koenderman L, Hordijk PL, Zwaginga JJ: Platelet-monocyte complexes support monocyte adhesion to endothelium by enhancing secondary tethering and cluster formation. Arterioscler Thromb Vasc Biol 2004, 24:193-199.

26. Morabito S, Guzzo I, Solazzo A, Muzi L, Luciani R, Pierucci A: Continuous renal replacement therapies: anticoagulation in the critically ill at high risk of bleeding. J Nephrol 2003, 16:566-571.

27. Koster A, Chew D, Merkle F, Gruendel M, Jurmann M, Kuppe $H$, Oertel R: Extracorporeal elimination of large concentrations of tirofiban by zero-balanced ultrafilration during cardiopulmonary bypass: an in vitro investigation. Anesth Analg 2004 99:989-992.

28. Steinhubl SR, Tallex JD, Braden GA, Tcheng JE, Casterella PJ, Moliterno DJ, Navetta FI, Berger PB, Popma JJ, Dangas G, Gallo R, Sane DC, Saucedo JF, Jia GJ, Lincoff M, Theroux P, Holmes DR, Teirstein PS, Kereiakes DJ: Point-of-care measured platelet inhibition correlates with a reduced risk of an adverse cardiac event after percutaneous coronary intervention. Results of the GOLD (AU-Assessing Ultegra) multicenter study. Circulation 2001, 103:2572-2578. 